\title{
Trends in Early Childhood Education Practice and Professional Learning with Digital Technologies
}

\author{
Karen Murcia, Coral Campbell, George Aranda
}

\begin{abstract}
This literature-based article explores key trends in the integration of digital technologies in education and aims to highlight issues and challenges in the relationship between technology, pedagogy and early years' education practices. The article explores how technology, teacher training initiatives and productive play-based pedagogy could be used to improve digital literacy outcomes for early childhood learners. While situated within the Australian context, more global literature is also reviewed to provide an international perspective. This review of trends in the integration of digital technologies in education is timely due to the national and international focus on STEM (Science, Technology, Engineering and Mathematics) education, arguably for economic sustainability and the quality standards expected in early childhood education. The role of digital technologies in early childhood is increasingly discussed and negotiated in learning centres. Educators are wanting support in understanding how young children can be creators of technology rather than simply being consumers of digital products.
\end{abstract}

Keywords: digital technology, tangible coding technologies, early childhood education, teacher training, pedagogy.

\section{INTRODUCTION}

Australian governments have invested extensively in digital education highlighting the growing link between technology and economic prosperity (Digital Education Advisory Group, 2012). In 2008, the Digital Education Revolution was a driver for transforming teaching and learning through digital education and focused on all aspects of education from teacher training and professional learning to digital re- sources, curriculum design and community engagement (Digital Education Advisory Group, 2012). It was proposed through this initiative that digital technologies should be used to enhance social inclusion and facilitate child-centred learning in both formal and informal learning environments. The drive to provide quality teaching and learning through digital education was supported by a $\$ 2.1$ billion Digital Education Revolution. This initiative went beyond simply providing computers to 
schools by including the design of digital learning resources, online diagnostic tools and professional development for teachers. This multi-pronged strategy aimed to reshape how students learn and even what they learn through powerful $21^{\text {st }}$ century tools. The initiative encouraged reform to education systems and for educators to see the opportunities that digital technologies provide to support improved learning and teaching.

Additionally, in 2011, the Department of Education, Employment and Workplace Relations of the Australian Government, through the ICT Innovation Fund, provided money for the Teaching Teachers for the Future (TTF) project which was aimed at improving the proficiency of all pre-service teachers at early, middle and senior teaching levels in the use of ICT (Information and Communication Technologies) in education. The project involved all 39 Australian teacher education institutes and specifically directed systemic change in pre-service teacher education by building the capacity of teacher educators and through the development of online resources to provide rich professional learning. The project targeted the development of educators' 'technological pedagogical content knowledge' (TPCK - also known as TPACK). With an awareness that effective educators are those who can draw on deep knowledge of a subject and combine that with a strong understanding of 'how to teach', the TTF project aimed to fuse these components within a pedagogy which incorporated ICT understandings of how to access and process knowledge in new ways, using appropriate tools (technology). This transformation of pedagogy is enhancing the engagement of pre-service teachers, "initial teacher education students are now more likely to demonstrate TPACK as future teachers" (Romeo, Lloyd \& Downes, 2012, p. 960).

In addition to the targeting of preservice teachers, the TTF project provided support to in-service teachers which was practitioner-based and was used to continuously transform teaching experiences and practices. Phillips (2017) indicates that models of professional learning aimed at improving teachers' understandings of digital technologies and how to implement them with pedagogical and content knowledge, often fall short of addressing the complexity of teachers' workplaces. The research found that contextual factors influenced in-service teachers' development and enactment of digital technologies. Considerations of identity development and practice, a teacher's community of practice, enactment of digital technologies, challenges of mutuality and shared understanding, all impact on the development of digital understandings and TPACK.

Despite this national agenda and investment in resources there are no clear frameworks for the integration of digital technologies into early years education. To assist, Early Childhood Australia (2018) has released a statement on young children and digital technologies to inform educators' practice (Edwards, Straker \& Oakey, 2018). This statement should provide much-needed principles and advice 
for educators wanting to integrate digital technologies into young children's learning experiences. Internationally, an earlier American statement produced by the National Association for the Education of Young Children and Fred Rogers Centre (2012) reminded us of the need for critical reflection on the use of digital technologies. It states, "technology and media are tools that are effective only when used appropriately" (p. 4). Research is needed to ensure educators' pedagogy with technology is based on evidence and provides learning experiences that promote young children's cognitive, and socio-emotional development (Zabatiero et al., 2018).

Given this agenda and need, the paper will discuss digital technologies in the early childhood (EC) education sector. It will provide a critical review of the opportunities and demands facing educators who are working to integrate digital technologies into the early childhood learning environment.

\section{What Constitutes 'Digital Technology' in Education?}

In the rapidly-evolving technological world teachers can feel overwhelmed with the choices and range in the types of educational technologies available. The Victoria State Government, on their Education and Training website (2018) described digital technologies as 'electronic tools, systems, devices and resources that generate, store or process data'. These may include social media, online games and applications, multimedia, productivity ap- plications, cloud computing, interoperable systems and mobile devices. Digital learning was further described as any type of learning that is facilitated by technology or by instructional practice that makes effective use of technology. Digital learning occurs across all learning areas and domains. It encompasses the application of a wide spectrum of practices including: blended and virtual learning, game-based learning, accessing digital content, collaborating locally and globally, assessment and reporting online, active participation in online communities, using technology to connect, collaborate, curate and create.

The Australian curriculum, The Technologies: Digital technology (ACARA, 2015), discusses the competencies required by teachers to implement the digital technologies curriculum. The specified elements of the digital technologies with which a teacher should be competent include a knowledge and understanding of digital systems and data representations and well as the processes and production skills required to collect and manage data, and creating digital solutions to problems. According to the Australian curriculum, teachers should be able to adequately guide young children to develop digital literacy and computational thinking. This incorporates the development of understanding between real and virtual worlds, the use of technology in communication and the importance of precise instructions and simple problem-solving in the digital world (Falkner \& Vivian, 2015). This means that teachers themselves must have a similar level of competency. They should 
demonstrate capable and critical use of the digital technologies in areas of ICT and problem solving.

White and Le Cornu (2011) propose that teachers who are required to teach digital technologies need to prepare themselves by becoming more involved with the digital world at a personal, as well as professional level. For teachers to be able to enhance children's learning and develop children's knowledge, they must have a repertoire of knowledge and skills built through their own lives. Albion, Campbell and Jobling (2018, p. 295) claim that "teachers who created digital solutions to meet needs in their own lives will be better equipped to engage their classes...”. In Europe, a framework for clarifying teachers' digital competencies has been developed which considers professional engagement, digital resources, digital pedagogy, digital assessment, empowering learners and learners' digital competence. These components are considered across a continuum of increasing capability (European Commission, 2017).

\section{Digital Aspects of Early Childhood Education}

There is at least a 30-year history of research which has focused on young children's ability to code which started with Seymour Papert's computer language logo turtle which was a tool to improve the way children think and solve problems (Albion et al., 2018). Internationally, the digital revolution of the last 20 years has heightened interest and also influenced early childhood (EC) education and technologies, which are now widely considered a significant aspect of young children's learning (Berson \& Berson, 2010). In the United States, for example, the percentage of young children reported to have ongoing access to digital devices has increased to a staggering $98 \%$ in 2017 (Miller et al., 2017). Yet there is research evidence suggesting educators may be restricting children's access to technology in early childhood centers (Highfield, Paciga \& Donohue, 2018). One concern may be due to research which has reported that integration into EC teaching is still difficult to achieve as concerns are raised in relation to the place of digital technologies in traditionally-valued forms of play-based learning (Edwards \& Bird, 2015; Edwards, 2016). Research (Bird \& Edwards, 2016, p. 1150) indicated that there was a sense by educators that the use of technologies in early childhood, as either 'play with technologies' or 'learning technologies through play', could restrict children's imagination. A recent American research study (Radesky \& Christakis, 2016) suggests that electronic 'toys', designed to assist young children's learning, may in fact be decreasing the quantity and quality of a baby's language. Another reason for restricting access to technology in EC centres may have to do with parental concerns about their children's use of digital technology. In a study examining children and their families' experiences with digital technologies in seven European countries (Chaudron, 2015), it was reported that parents could not always see the benefits of children using digital 
technology, when compared to the risks of being exposed to inappropriate or unwanted content, and conflicting messages about how much screen time children should engage in. Given such conflicting information, it is difficult for EC educators to determine just what is best for children in their centres.

Barriers in early EC could be overcome by developing new ideas about children's digital play that helps educators recognise children's activities with technologies in a play-based way (Edwards, 2013). Researchers have argued that 'computer science is well-suited for early childhood education as it offers a learning environment where young children can 'play to learn while learning to play' (Bers et al., 2014, p. 146). In a play-based learning environment, young children engaged in simple coding or early programming should have the opportunity to explore and experience problem-solving, computational thinking and mathematical reasoning involving measurement, spatial awareness and geometric visualization, when supported by well-designed and developmentally appropriate digital technologies.

An alternate method of engaging children in ideas about computational thinking is to engage them in non-computational activities, for example, those advocated by programs such as the popular CS Unplugged (https://csunplugged.org). This program aims to engage children in computer science concepts using 'hands-on' activities such as drawing, role-play and interacting with physical objects (Computer Science Unplugged, 2015). The program was designed for primary school aged children, but has been successfully used with students of all ages (Bell, 2016), and has been linked to more positive attitudes to computer science in students and teachers (Lambert \& Guiffre, 2009; Blum \& Cortina, 2007). However, researchers such as Marina Bers have claimed that students should not focus on exploration of computational thinking concepts in the absence of coding (Bers, 2012). Using the metaphor of the play, she believes that learning about computational thinking without creating a program is akin to having students in a restrictive 'playpen', whereas true exploration of these ideas requires students expressing themselves in a 'playground'. So, while she acknowledges that exploration within the playpen will take you so far, she feels that students need interaction and engagement with an external digital object for effective learning about computational thinking. This is part of the ongoing debate about digital technologies in early childhood - educators want to know how to integrate technologies, what to do and when to do it. If we follow the reasoning of Bird and Edwards (2015, p. 1150) in which they propose that initially children needed to 'play' with digital technologies before being able to use them to create new play experiences, we need to consider how unplugged technologies might fit with this.

The various types and design style of educational technologies make some more suited to an early years learning environment than others. For example, researchers have observed young children becoming 
socially isolated when they are focused on a screen, yet when playing with tangible coding technologies such as Bee-Bot and Cubetto they collaborated and communicated with others as they coded the actions of the 'robot' (Murcia \& Pellicione, 2017). Similar results were reported by Pekárková (2008) who reported Bee-Bots being used by kindergarten children, working together in large groups and persevering to try to solve their task. Danby (2017) also found that young children's familiar use of mobile electronic devices can promote successful social interaction. Consideration should be given to both the type of digital technology introduced and how it can be effectively integrated into the EC learning environment and used to support and enhance the EC focus on social-emotional learning and play.

\section{Computational Thinking and Tangible Coding}

\section{Technologies}

Coding is regarded as one of the most powerful aspects of educational technology and contributes to the development of technological literacy which includes skills related to computational thinking (Strawhacker, Lee \& Bers, 2018). Computational thinking has many definitions and encompasses a broad range of analytic and problem-solving skills, dispositions, habits and approaches used in computer science. It involves the ability to recognise how computational instructions cause computational behaviour while also de- veloping the ability to identify potential 'bugs' and error sites. When children learn a programming language they are solving problems in systematic ways, learning new powerful ideas and expressing themselves with a variety of computational media (Sullivan \& Bers, 2015). Computational thinking is strategic in nature and includes the ability to break a large problem into smaller parts for analysis (Gadzikowski, 2018). For example, young children demonstrate computational thinking when they break a task into its parts such as planning how to move a 'robot' through an obstacle course; questioning and deciding about distance, direction and relative efficiency of potential pathways.

Bers (2018) proposes that there are seven powerful ideas that can be focused on in teaching computer science in early childhood: algorithms, modularity (decomposition), controls structures (pattern recognition and conditionals), representation (data representation), hardware/software (systems thinking), design process and de-bugging. The terms in brackets are reflective of how they are discussed within computational thinking models such as those presented by Wing (2006) or more broadly within the Australian digital technologies curriculum (ACARA, 2015). Bers (2018) discusses the relevance of the first five ideas as those that would be foundational at early years and need to be clearly linked to develop learning across a variety of disciplines. The latter two big ideas are related specifically to technology and digital technologies, and Bers makes the distinction that de-bugging should only be 
considered relevant to coding, although it could be argued that de-bugging has great utility across different disciplines as well.

Initially, there were few digital technologies specifically designed for developing young children's coding capabilities. Early and significant developments occurred in the LOGO educational programming environment of the late 1970 's. LOGO programming was described by Strawhacker et al. (2018), as one of the most influential coding tools to inform the design and theory behind new technological tools. The ScratchJr program was a direct descendant of the LOGO programs and was designed as a developmentally appropriate tool for children between the ages of 5-7. ScratchJr is an open-ended coding environment that allows children to create self-directed and interactive projects, stories and games. Children interact with the coding environment through a computer or digital interface such as an iPad. While using this program children have been able to master core programming concepts, including sequencing, looping procedures, and parallel programming (Flannery et al., 2013). However, little is documented about how teachers use these tools in their schools and the learning outcomes that children can achieve when lessons are taught by teachers (rather than researchers). ScratchJr is being incorporated into professional development for EC educators as it is recognised that EC educators are often not confident with teaching digital technologies and are unlikely to incorporate it into their teaching. Kalogiannakis \& Papadakis (2017) reported improvements in pre-service teachers' confidence in teaching computational thinking and a greater sense of the program's usefulness after using ScratchJr for a semester.

In addition, few robotics kits were initially available specifically designed for early learners with building and programming capabilities. The WeDo 2.0 is a well-recognised commercial product designed for primary school aged children that combines Lego bricks with coding software. The coding software in its robotics kit uses a drag and drop action on a digital screen interface. This welldesigned robotics kit was not intended for young children and as such it doesn't include design features specific to early childhood. Alternatively, the development of KIWI by the DevTech Research Group used CHERP (Creative Hybrid Environment for Computer Programming) and targeted the learning capabilities of young children. CHERP was a tangible programming language consisting of interlocking wooden blocks. Teacher's feedback during the product design and development was considered and prompted researchers to create a product which does not require any screen-time or computer to be programmed. Arguably, Tangible Coding Technologies (TCTs) benefit young children's learning as they have tangible controllers which allow the robot to be programmed without the need for a computer screen or digital interface.

The design of coding tools for young children that are independent of a digital screen interface has progressed and more are commercially available. There has also 
been an increase in the number of tangible programming languages available with the rise of cheaper and more sophisticated tangible technology (Bers, 2018). These TCTs or 'robots' are specifically designed for young children ages 3-7 (although more sophisticated versions could be used by older children), introduce the building blocks of computer programming and computational thinking which are key to empowering learners as creators of technology rather than simply being consumers of a product (Elkin, Sullivan \& Bers, 2014). Through play with TCTs, children use tangible controllers, such as pressing physical buttons or picking up and ordering blocks to make their robot perform actions. KIBO, an early example of a tangible technology was originally programmed using wooden blocks that the robot examined using an embedded scanner (Bers, 2018). Instead of using text as the basis of the programming language, icons were depicted and because of the physical nature of the blocks, it allowed young children to rearrange the blocks (something they were most likely already familiar with) to give commands to the robot. By rearranging the blocks in this way, they were engaging in issues of sequencing and patterns that may be difficult concepts to grasp when working with screens. Recent studies of commercial TCTs, such as Cubetto and Bee-bots, indicates that foundation coding experiences become more accessible to young children through the use of these tangible tools (Highfield, 2014; Murcia \& Pellicione, 2017). These studies indicate that through engagement with these tangible tools, young learners are engaged in collaboration and problem-solving with tangible interfaces.

\section{Developing Educators' Competencies in Digital Pedagogies}

It is apparent through international research and practice that many early childhood educators lack confidence and knowledge about digital technologies (including engineering) and developmentally appropriate pedagogies for integrating them into the learning environment. Educators often do not have a strong understanding of the digital or ICT skills needed to guide young children's play with tangible coding technologies (Campbell et al., 2018). However, educators with a positive attitude as well as high self-confidence towards technology are more likely to use technologies in the learning environment (Holden \& Rada, 2011). Programs such as CS Unplugged have been beneficial to teachers in providing them the opportunity to develop their understanding of computational thinking and how to teach it, without the encumbrance of learning a programming language. After completing a workshop focused on CS Unplugged activities, high school teachers reported increased confidence in teaching concepts related to computational thinking (Blum $\&$ Cortina, 2007). Hence well-designed professional learning is needed to assist early childhood educators to build techno- 
logical content knowledge and age appropriate pedagogical practices aligned with a play-based philosophy.

International research by Bers, Seddighin, \& Sullivan (2013) proposed that robotics or TCTs could provide a playful bridge for integrating teacher's development of technological pedagogical content knowledge' with children's learning projects. Bers et al. (2013) aimed to increasing early childhood teachers' knowledge about robotics, engineering and programming through a professional development study. The design of the study brought together technology and engineering in EC learning through the introduction of robotics. As an outcome, it was proposed that successful professional learning included both technological content and pedagogical knowledge. It was also evident to the researchers that to have a significant impact on teacher's classroom practice the professional learning needed to include opportunities for active learning and coherence with other discipline content knowledge.

To elaborate, Bers et al. (2013) used the Technological Pedagogical Content Knowledge (TPCK) framework to interpret the teachers' development. The Content Knowledge (CK) domain included robotics as a subject matter, which included the engineering aspects of building an artefact able to move and sense the environment, and also the programming which determined behaviour sequences the actions and responses. The Pedagogical Knowledge (PK) captured the strategies and methods of teaching engineering and technology content using developmentally appropriate pedagogies, while Technological Knowledge (TK) involved the broader understanding of technology education and the transferable skills and concepts from the robotics experience. Teachers' development of Technological Pedagogical Content Knowledge (TPCK) was represented at the intersection of CK, PK and TK.

This research study used KIWI technology (Kids Invent with Imagination) a prototype developed by the DevTech Research Group and CHERP tangible programing language. The researchers claimed the professional learning event increased the participating teacher's technology, pedagogy and robotic content knowledge and importantly their technology self-efficacy and attitudes toward integrating digital technology into the early years learning environment. Interestingly, the professional learning program was more beneficial for teachers who began with lower levels of knowledge and self-efficacy and more negative attitudes toward technologies than teachers who began with higher levels of each of these.

More recently, Strawhacker et al. (2018) investigated the effect of teacher preparation and instructional style on the learning outcomes achieved by children when engaging with new technology. It was highlighted, that the success of programming curricula in the early years was not as dependent on the availability of technology as it was on appropriately designed learning activities and supporting materials which were integrated into ev- 
eryday practice by well informed and prepared teachers. Diverse teaching approaches and skills were identified and inferred to be impacting on children's learning in the technology area. Teachers participating in this study, regardless of their own teaching style, believed the professional learning interventions were a success because of its open-ended design and support for different approaches to integrating technologies into the learning environment. As is the case for children's learning in other key areas (e.g. science, humanities, literacy, mathematics), the educator's knowledge and understanding is paramount to being able to scaffold children's learning effectively. Researchers Newhouse, Cooper, \& Cordery (2017) also found that without some explicit scaffolding from an educator, young children in early years classrooms did not typically demonstrate actions associated with computational thinking. However, they did demonstrate motivation and increased engagement when using the programmable digital toys (Bee-Bots \& Spheros) in play-based learning experiences. Hence, whether through guided participation or co-learning with the child, the role of the adult as a 'more knowledgeable other' is recognised through Vygotskian perspectives as important for moving children into a higher level of understanding.

Initial teacher education programs are incorporating a number of the requisite skills through the embedding of digital technologies into the teaching curriculum. Higher education students are provided with opportunities to engage with digital technology devices (such as Bee-Bots,
Spheros, Cubetto, Aquinis) and are expected to use a range of ICT devices for communicating within their own studies. In specific units of study, such as mathematics education, a focus on computational thinking and coding has been provided. All initial teacher education programs must ensure that graduating teachers meet the Australian Institute for Teaching and School Leadership (AISTL) Professional standards of teachers. Three of these professional standards focus on a teacher's competency in ICT skills, with specific mention of the associated skills required (AITSL, 2015)

Internationally, various governments and education providers are considering ways to improve children's learning in digital technologies through teacher education programs. For example, in Europe, the European Commission (2018) is advocating that teacher education requires an approach that combines teacher training, curricula development and effective educational materials. Teachers need to work through networks which support them and provide opportunities for the sharing of learning. The European Commission has created the SELFIE self-assessment tool, based on the digital technologies' competencies required for teachers (European Commission, 2017: Digital Competence Framework for Educators, https:// ec.europa.eu/jrc/en/digcompedu) which enables teachers to monitor and self-regulate their learning needs. The European Commission states "Acquiring digital skills needs to start at early age and carry on throughout life" (2018, p. 7). 


\section{Professional Learning Programs in Early Childhood EDUCATION}

Professional learning programs in early childhood often arise through the various regulatory bodies and are frequently targeted towards fulfilment of new policy directions such as mentoring, literacy or numeracy. However, a recent Australian study has shown that EC educators are interested and keen to develop competencies in STEM and digital technologies (Campbell et al., 2018). However, for EC educators already in practice, there is a reliance of additional professional learning through external providers. To date, this professional learning is scarce and is not necessarily targeting educator knowledge but has a focus on providing opportunity for educators to experience the digital technologies themselves and to share their developing understandings in collaboration with other teachers.

Specific professional learning programs for the development of digital technology skills in early childhood are not very prominent in Australia. However, there has been national government support for the provision and research of developed programs such as 'Count On' (mathematics education), 'Little Scientist' (science education) and ELSA (digital apps) (Birmingham, 2016). Similarly, there have been small isolated research projects which have investigated the use of various digital devices in early childhood, but very little research literature generated about addressing early childhood educators' professional learning needs.

In 2017, Education Services Australia (ESA), for the Australian Government Department of Education and Training, developed an informal online repository known as the Digital Technologies Hub (ESA, 2018). This hub provides a place for teachers, school leaders, students and families to gain and share information and resources to create a more enhanced understanding of pedagogy in digital technologies. In particular, it provides support for teachers to navigate the digital technology world, proving scope and sequence charts to map children's skills and achievements. The website states that the hub "aims to support the implementation of quality Digital Technologies programs and curriculum in schools and to support after school activities". The hub is supported by a wide range of people including teachers of digital technologies, university academics, those involved with professional teacher associations and industry. It is a dynamic space with content changing frequently - new content and resources are developed to support the implementation of digital technologies in teaching. For a teacher, new to digital technologies, there is much opportunity to learn from the vast array of material available on line. However, at this time, the site does not specifically address pre-school learning. It provides information for teachers working with children 5-16 years of age and is aligned with the Australian Curriculum F-10 in the Technologies: digital technologies. As such there is material available for working with 
children aged 5-8, which could be adapted for younger children. The information relating to educator skills would be gleaned through the multiple resources available but is much less specific.

Given the tendency for local development of digital technology programs, related teaching and learning approaches vary according to the structures and priorities of individual centres, needs of children and educators' knowledge and pedagogy (Campbell et al., 2018). While digital technology programs and pedagogies are becoming available through pre-determined packages (e.g. Little Scientists), the challenge is to develop a coherent framework to guide EC educators' in teaching and learning. Early childhood digital technology is a field of research that is in its infancy with insufficient support to provide educators with targeted knowledge and skills.

\section{Conclusion}

This paper sets out to discuss the focus on digital technologies in early childhood. Through the interrogation of specific aspects, it provides a critical review of the opportunities and demands facing early childhood educators who are working towards the integration of digital technologies in early childhood environments. Firstly, digital technologies and the professional knowledge linked to teaching with, and for, digital technologies are defined within an educational context using Australian curriculum frameworks and the professional standards of teachers. This is supported with a brief introduction for the European teacher digital standards. It is quite clear that there is still some broader debate around the value of introducing digital technologies into a play-based emergent curriculum as the current early years' framework is not specific enough to consider it a mandated aspect of the early years curriculum. In addition, teachers need to develop competencies themselves to feel confident and capable to design and develop learning activities for children.

The aforementioned discussion acknowledges the value of digital technologies in early childhood. Digital technologies in early childhood can support young children's development of problem-solving and computational thinking. In particular, tangible coding technologies are recognised as providing young children with opportunities to learn to code in a playful situation, while supporting collaborative learning and social interaction.

Developing teachers' and educators' capabilities in digital technologies is somewhat problematic. In-service programs are minimal and the most significant aspect of these is that they tend to be formulaic, without consideration of the context required for improved professional learning. Professional learning, at the point of need, is required for teachers to develop requisite competencies. The success of digital technology curricula in EC education is not so dependent on the availability of technology as it is on appropriately designed activities and supporting materials integrated into learning environments by wellinformed and prepared educators. 


\section{REFERENCES}

Albion, P., Campbell, C., \& Jobling, W. (2018). Technologies education for the primary years. Cengage. Melbourne.

ACARA. (2015). Australian curriculum: Technologies. Canberra: Australian Curriculum, Assessment and Reporting Authority. Retrieved from http://www.australiancurriculum.edu.au

AITSL. Australian Institute for Teaching and School Leadership. (2015). Accreditation of initial teacher education programs in Australia, standards and procedures. Melbourne: AITSL. Retrieved from www.aitsl.edu.au

Bell, T. (2016). The research files special episode: professor Tim Bell (J. Earp Interviewer). [Interview transcript]. Retrieved from www.teachermagazine.com.au/articles

Bers, M. U. (2012). Designing digital experiences for positive youth development: From playpen to playground. Cary, NC: Oxford.

Bers, M. U. (2018). Coding as a playground: Programming and computational thinking in the early childhood classroom. New York: Routledge.

Bers, M., Flannery, L., Kazakoff, E., \& Sullivan, A. (2014). Computational thinking and tinkering: Exploration of an early childhood robotics curriculum. Computers and Education, 72, 145-157.

Bers, M., Seddighin, S., \& Sullivan, A. (2013). Ready for robotics: Bringing together the T and E of STEM in early childhood teacher education. Journal of Technology and Teacher Education, 21(3), 355-377.

Berson, I. R., \& Berson, M. J. (Eds.) (2010). High-tech tots: Childhood in a digital world. Charlotte, NC: Information Age.

Bird, J., \& Edwards, S. (2015). Children learning to use technologies through play: A Digital Play Framework. British Journal of Educational Technology, 46(6), 1149-1160.

Birmingham, S. (2016). STEM head start for 350,000 pre-schoolers. Media Release, Minister for Education and Training, 8 February 2016.

Blum, L., \& Cortina, T. (2007). CS4HS: An outreach program for high school CS teachers. Proceedings of the $38^{\text {th }}$ ACM Technical Symposium on Computer Science Education, New York (19-23).

Campbell, C., Speldewinde, C., Howitt, C., \& MacDonald, A. (2018). STEM practice in the early years. Creative Education Journal Special Edition Preschool Education Research, 9(1), 11-25.

Chaudron, S. (2015). Young children (0-8) and digital technology: JRC Science and Policy Reports. (Report No. EUR 27052 EN). Retrieved from http://publications.jrc.ec.europa.eu

Computer Science Unplugged (2015). Retrieved from https://csunplugged.org

Danby, S. (2017). Technologies, child-centred practice and listening to children. In Arnott, L. (Ed.) Digital technologies and learning in the early years (127-138). London: SAGE.

Digital Education Advisory Group. (2012). Beyond the classroom: A new digital education young Australians in the 21st century. Retrieved from https:/docs.education.gov.au 
Early Childhood Australia (ECA). (2018). Statement on young children and digital technologies. Canberra, ACT: ECA.

ESA. Education Services Australia. (2018). Digital Technologies Hub. Retrieved from www. digitaltechnologieshub.edu.au

Edwards, S. (2013). Digital play in the early years: a contextual response to the problem of integrating digital technologies and play based learning in the early childhood curriculum. European Early Childhood Education Research Journal, 21(2), 199-212.

Edwards, S. (2016). New concepts of play and the problem of technology, digital media and popular-culture integration with play-based learning in early childhood education. Technology, Pedagogy and Education, 25(4), 513-532.

Edwards, S., \& Bird, J. (2015). Observing and assessing young children's digital play in the early years: Using the Digital Play Framework. Journal of Early Childhood Research, 15(2), 39-49.

Edwards, S., Straker, L., \& Oakey, H. (2018). Early Childhood Australia. Statement on young children and digital technolgies. Canberra, ACT: ECA.

Elkin, M., Sullivan, A., \& Bers, M. (2014). Implementing a robotics curriculum in an early childhood Montessori classroom. Journal of Information Technology Education: Innovations in Practice, 13, 153-169.

European Commission. (2017). Assessing Educators' Digital Competence. Retrieved from https://ec.europa.eu

European Commission. (2018). Communication from the commission to the European parliament, the council, the European economic and social committee and the committee of the regions on the Digital Education Action Plan. Retrieved from https://ec.europa.eu

Falkner, K., \& Vivian, R. (2015). Coding across the curriculum: Resource review report. Final report. Computer Science Education Research Group. University of Adelaide. Retrieved from https://docs.education.gov.au

Flannery, L., Kazakoff, E., Bontá, P., Silverman, B., Bers, M. U., \& Resnick, M. (2013). Designing ScratchJr: Support for early childhood learning through computer programming. In Proceedings of the $12^{\text {th }}$ International Conference on Interaction Design and Children (1-10). New York, NY: ACM.

Gadzikowski, A. (2018). Robotics for young children: STEM activities and simple coding. Redleaf Press.

Highfield, K. (2014). Stepping into STEM with young children: simple robotics and programming as catalysts for early learning. In C. Donohue (Ed.), Technology and digital media in the early years: Tools for teaching and learning (150-160). Taylor \& Francis.

Highfield, K., Paciga, K. A., \& Donohue, C. (2018). Supporting whole child development in the digital age. In S. J. Danby, M. Fleer, C. Davidson, \& M. Hatzigianni (Eds.), Digital childhoods: Technologies and children's everyday lives (165-182). Singapore: Springer. 
Holden, H., \& Rada, R. (2011). Understanding the influence of perceived usability and technology self-efficacy on teachers' technology acceptance. Journal of Research on Technology in Education, 43, 343-367.

Kalogiannakis, M., \& Papadakis, S. J. (2017). Pre-service kindergarten teachers' acceptance of "ScratchJr" as a tool for learning and teaching computational thinking and science education. In Proceedings of the 12th Conference of the European Science Education Research Association (ESERA), Research, practice and collaboration in science education (21-25). Dublin, Ireland: Dublin City University and the University of Limerick.

Lambert, L., \& Guiffre, H. (2009). Computer science outreach in an elementary school. Journal of Computing Sciences in Colleges Archive, 24(3), 118-124.

Miller, J. L., Paciga, K. A., Danby, S., Beaudoin-Ryan, L., \& Kaldor, T. (2017). Looking beyond swiping and tapping: Review of design and methodologies for researching young children's use of digital technologies. Cyberpsychology: Journal of Psychosocial Research on Cyberspace, 11(3), article 6.

Murcia, K., \& Pelliccione, L. (2017). Early childhood iSTEM: Playing as learning with digital technology toys. Presented at Digitising Early Childhood International Conference, Perth, Western Australia.

National Association for the Education of Young Children (NAEYC) and Fred Rogers Center for Early Learning and Children's Media. (2012). Position statement: Technology and interactive media as tools in early childhood programs serving children from birth through age 8. Retrieved from www.naeyc.org

Newhouse, C. P., Cooper, M., \& Cordery, Z. (2017). Programmable toys and free play in early childhood classrooms. Australian Educational Computing, 32(1).

Pekárková, P. (2008). Using a programmable toy at preschool age: Why and how? In Workshop Proceedings of SIMPAR 2008 (112-121). International Conference on Simulation, Modeling and Programming for Autonomous Robots, Venice (Italy) 2008 November, 3-4.

Phillips, M. (2017). Processes of practice and identity shaping teachers' TPACK enactment in a community of practice. Education and Information Technologies, 22(4), 1771-1796.

Radesky, J., \& Christakis, D. (2016). Keeping children's attention: The problem with bells and whistles. JAMA Pediatrics, 170(2), 112-113.

Romeo, G., Lloyd, M., \& Downes, T. (2012). Teaching Teachers for the Future (TTF): Building the ICT in education capacity of the next generation of teachers in Australia. Australasian Journal of Education Technology, 28(6), 949-964.

Strawhacker, A., Lee, M., \& Bers, M. U. (2018). Teaching tools, teachers' rules: Exploring the impact of teaching styles on young children's programming knowledge in ScratchJr. International Journal of Technology and Design Education, 28(2), 347-376.

Sullivan, A., \& Bers, M. U. (2015). Robotics in the early childhood classroom: learning outcomes from an 8-week robotics curriculum in pre-kindergarten through second grade. International Journal of Technology and Education. (Online). 
Victoria State Government: Education and Training. (2018). Digital learning. Retrieved from www.education.vic.gov.au

White, D. S., \& Le Cornu, A. (2011). Visitors and residents: A new typology for online engagement. First Monday, 16(9).

Wing, J. M. (2006). Computational thinking. Communications of the ACM, 49, 33-35.

Zabatiero, J., Mantilla, A., Edwards, S., Danby, S., \& Straker, L. (2018). Young children and digital technology: Australian early childhood education and care sector adults' perspectives. Australasian Journal of Early Childhood, 43(2), 14-22.

Karen Murcia (Australia), Curtin University, School of Education;

e-mail: karen.murcia@curtin.edu.au

Coral Campbell (Australia), Deakin University, School of Education;

e-mail: coral.campbell@deakin.edu.au

George Aranda (Australia), Deakin University, School of Education;

e-mail: george.aranda@deakin.edu.au 